\title{
$\mathrm{SF}_{6}$ 가스 중 직류 고전압 하에서 부분방전 특성
}

\author{
김민수 ${ }^{1}$, 김선재 ${ }^{1}$, 정기우 ${ }^{1}$, 조향은 ${ }^{1}$, 길경석 ${ }^{1, a}$ \\ 1 한국해양대학교 전기전자공학과
}

\section{Characteristics of Partial Discharge Under HVDC in $\mathrm{SF}_{6}$ Gas}

\author{
Min-Su Kim ${ }^{1}$, Sun-Jae Kim ${ }^{1}$, Gi-Woo Jeong ${ }^{1}$, Hyang-Eun Jo $^{1}$, and Gyung-Suk Kil ${ }^{1, a}$ \\ ${ }^{1}$ Division of Electrical and Electronics Engineering, Korea Maritime and Ocean University, \\ Busan 606-791, Korea
}

(Received March 17, 2014; Accepted March 24, 2014)

\begin{abstract}
This paper dealt with the measurement and analysis of partial discharge (PD) under high voltage direct current (HVDC) in $\mathrm{SF}_{6}$ gas. Electrode systems such as a protrusion on conductor (POC), a protrusion on enclosure (POE), a crack on epoxy plate and a free particle (FP) were fabricated to simulate the insulation defects. The analysis system was designed with a Time-Frequency (T-F) map algorithm programed based on LabVIEW. This can arrange the acquired PD pulses into frequency and time domain. A HVDC power source is composed of a transformer $(220 \mathrm{~V} / 50 \mathrm{kV})$, a diode $(100 \mathrm{kV})$ and a capacitor $(50 \mathrm{kV}, 0.5 \mu \mathrm{F})$. The gap between the electrodes is $3 \mathrm{~mm}$, and the $\mathrm{SF}_{6}$ gas was set at 5 bar. PD pulses were detected by a $50 \Omega$ non-inductive resistor. In the analysis, PD pulses were distributed below $0.5 \mathrm{MHz}$ and $20 \mathrm{~ns} \sim 35 \mathrm{~ns}$ for the POC, $0.7 \mathrm{MHz} \sim 1.7 \mathrm{MHz}$, below $0.6 \mathrm{MHz}$ and $10 \mathrm{~ns} \sim 40 \mathrm{~ns}$ and $60 \mathrm{~ns} \sim 125 \mathrm{~ns}$ for the POE, below $0.1 \mathrm{MHz}$ and $135 \mathrm{~ns} \sim 215 \mathrm{~ns}$ for the crack, and below $1.6 \mathrm{MHz}$ and $250 \mathrm{~ns}$ for the FP.
\end{abstract}

Keywords: Partial discharge (PD), High voltage direct current (HVDC), $\mathrm{SF}_{6}$ gas, T-F map, Electrode systems

\section{1. 서 론}

급증하는 전력수요에 대응하고 전력수송비 절감, 전력공급의 신뢰도 향상 등을 위하여 전력계통의 초 고압·대용량화가 개발되고 있다. 최근 태양열, 풍력 등 신재생 에너지의 활용과 스마트 그리드에 대한 관 심이 증대되면서 직류 고전압 (HVDC) 송전에 대한

a. Corresponding author; kilgs@kmou.ac.kr

Copyright (C2014 KIEEME. All rights reserved.

This is an Open-Access article distributed under the terms of the Creative Commons Attribution Non-Commercial License (http://creativecommons.org/licenses/by-nc/3.0) which permits unrestricted non-commercial use, distribution, and reproduction in any medium, provided the original work is properly cited.
연구가 활발히 진행되고 있다. 장거리 송전 시 $\mathrm{HVDC}$ 방식은 전력손실이 적고 교류에 비해 절연이 용이하며, 주파수가 다른 국가와 계통연계가 가능하 여 점차 그 수요가 증가하는 추세이다 [1-4].

현재 미국과 유럽 등 선진국에서 신재생 에너지의 도입과 국가 간 계통연계를 위해 $\mathrm{HVDC}$ 의 적용을 추 진 중에 있으며, SIEMENS, $\mathrm{ABB}$ 및 $\mathrm{ALSTOM}$ 과 같 은 제조사를 중심으로 기술개발이 활발히 진행되고 있다. 국내에서도 제주-해남 간 $\mathrm{HVDC}$ 송전이 진행 중이며, 동북아 전력계통 연계 등의 중장기 계획이 수립되고 있다 [5].

외국의 경우 송전뿐만 아니라 $\mathrm{HVDC}$ 에서 사용되는 
전력설비의 진단기술에 관한 연구도 활발하게 진행되 고 있지만, 국내에서는 이제 관심을 갖기 시작했다. 전력설비 진단에 부분방전측정법이 주류를 이루고 있 으며, 교류에서는 정현파 위상과의 상관관계를 이용 하는 PRPD (phase resolved partial discharge) 분석 법이 적용되고 있다. 그러나 직류에서는 위상이 없으 므로 PRPD 분석법의 적용이 불가능하므로 이에 대 한 새로운 연구가 필요하다 [6,7].

본 논문에서는 $\mathrm{HVDC}$ 에 사용되는 전력설비 진단기 술 개발을 목적으로 $\mathrm{SF}_{6}$ 가스 중 절연 결함을 모의하 고, 검출된 부분방전 펄스를 시간 영역과 주파수 영 역으로 분석하여 결함별 특징을 도출하였다.

\section{2. 실험 방법}

\section{1 전극계}

전력설비의 절연결함은 제조과정에서 이물질의 혼 입, 전기적·기계적 스트레스 및 기타 환경적 요인에 의해 발생되며, 결함의 종류에 따라 부분방전의 발생 패턴이 다르게 분석된다 $[8,9]$. 전력설비에서 발생 가 능한 결함을 모의하기 위하여 도체 돌출 (protrusion on conductor, $\mathrm{POC}$ ), 외함 돌출 (protrusion on enclosure, POE), 크랙 (crack), 자유입자 (free particle, $\mathrm{FP}$ ) 형태의 전극계를 그림 1 과 같이 제작하 였다.

전극계는 지름 $125 \mathrm{~mm}$, 높이 $86 \mathrm{~mm}$ 인 원기둥의 밀폐형 구조이며, $\mathrm{SF}_{6}$ 가스를 최대 6 bar까지 봉입할 수 있다. 코로나를 방지하기 위하여 직류 고전압이 인가되는 접속부 상부에 직경 $30 \mathrm{~mm}$ 의 구갭을 설치 하였다.

(a)와 (b)는 전력설비 내부의 도체 및 외함 돌출 결 함을 모의한 것으로 전극계 내부에 사용된 침 전극은 곡률 반경이 $10 \mu \mathrm{m}$ 이며, 평판전극은 지름 $80 \mathrm{~mm}$, 두 께 $10 \mathrm{~mm}$ 로 가장자리를 둥글게 제작하여 전계 집중 을 방지하였다. (c)는 절연물에서 발생한 크랙을 모의 한 것으로 평판전극은 도체 돌출과 외함 돌출에 사용 된 전극과 동일하며, 고체절연물은 직경 $70 \mathrm{~mm}$, 두 께 $5 \mathrm{~mm}$ 의 에폭시를 사용하였다. (d)는 자유입자로 인한 결함을 모의한 것으로 입자의 직경은 $1 \mathrm{~mm}$ 로 서 구 형태의 알루미늄을 사용하였으며, 하부전극을 오목하게 하여 입자의 자유운동이 용이하도록 설계하 였다.
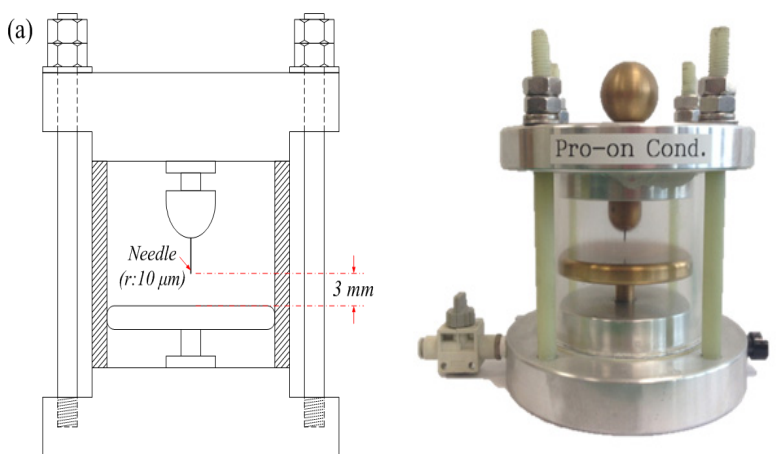

(b)

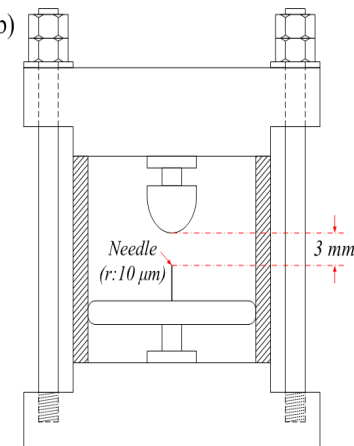

(c)

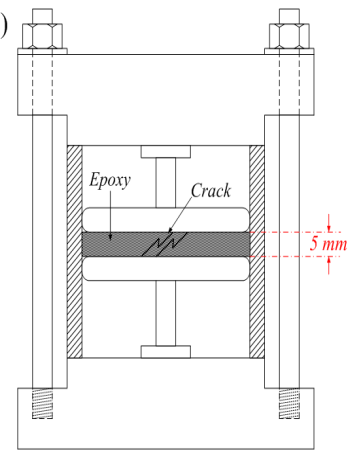

(d)

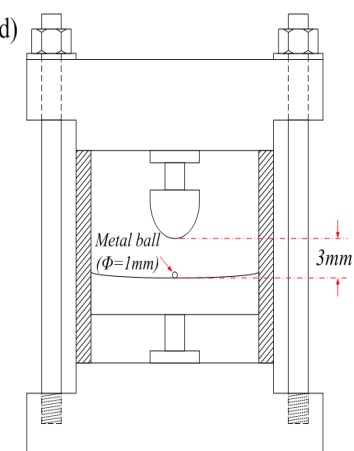

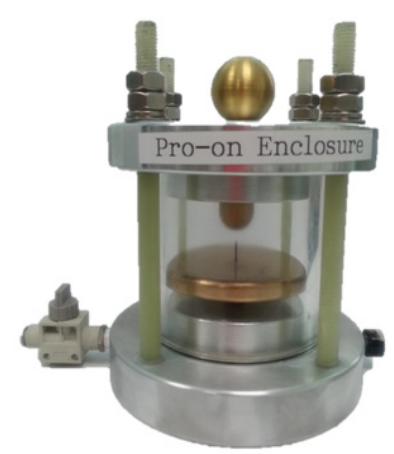
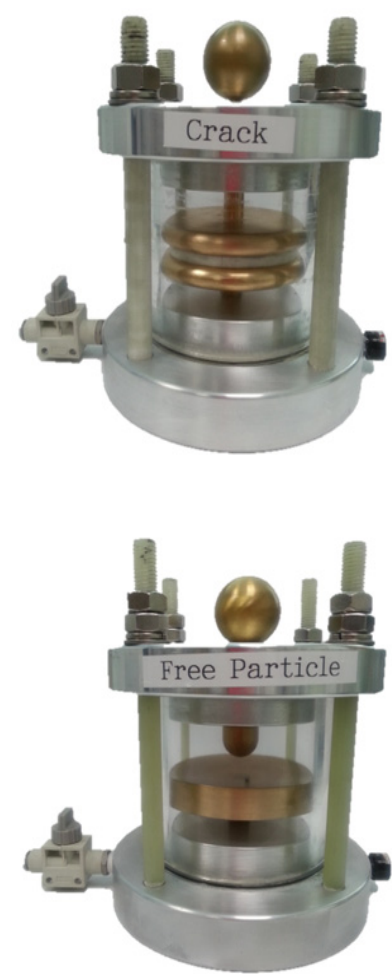

Fig. 1. Electrode systems. (a) POC, (b) POE, (c) crack, and (d) FP. 


\section{2 분석 시스템}

직류는 교류와는 다르게 위상이 없기 때문에 $\mathrm{PRPD}$ 분석법을 적용하는 것이 불가능하다. 그러나 $\mathrm{T}-\mathrm{F}$ map을 사용하면 부분방전 펄스를 시간 영역과 주파 수 영역으로 분포시켜 결함의 특징을 분석할 수 있다 [10-12]. 부분방전 펄스의 신호처리로 식 (1)과 같이 정규화 과정을 수행하였다 [13].

$$
\tilde{s}(t)=s(t) /\left(\sqrt{\int_{0}^{T} s(t)^{2} d t}\right) \quad \because s(t) \in[0, T]
$$

식 (2)와 식 (3)의 표준편차 수식을 이용하여 측정 된 신호를 이차함수로 나타내었으며, $\sigma_{T}$ 와 $\sigma_{F}$ 는 시간 과 주파수 영역에서 신호의 표준편차이다.

$$
\begin{gathered}
\sigma_{T}=\sqrt{\int_{0}^{T}\left(t-t_{0}\right)^{2} \tilde{s}(t)^{2} d t} \\
\sigma_{F}=\sqrt{\int_{0}^{\infty} f^{2}|\tilde{s}(f)|^{2} d f}
\end{gathered}
$$

$\tilde{s}(f)$ 는 $\tilde{s}(t)$ 의 퓨리에 변환으로 $t_{0}$ 는 정규화된 신호 의 무게 중심이며 식 (4)와 같이 표현된다.

$$
t_{0}=\int_{0}^{T} t \tilde{s}(t)^{2} d t
$$

상기 식을 이용하여 부분방전 펄스의 시간 및 주파 수에 대한 특징을 보존하고 $\mathrm{T}-\mathrm{F}$ map으로 분석하였다.

시스템은 RTOS (real time operating system)가 탑 재된 고속 데이터 수집 장치와 $\mathrm{LabVIEW}$ 로 설계한 $\mathrm{T}-\mathrm{F}$ map 분석 프로그램으로 구성되며 그림 2 와 같다. (a)는 front panel이며, (b)는 프로그램의 구성을 나타 낸 것으로 6 개 영역에서 신호 분석이 수행된다. (1)에 서 입력포트를 지정하고, (2)에서 신호를 분석하기 위 해 시스템을 설정한다. 데이터를 실시간으로 연속 처 리하는 방식은 메모리의 소모가 많으므로 (3)에서 분 석이 완료될 때까지 데이터 수집 장치의 내부 메모리 에 데이터를 저장하도록 하였으며, 측정 시간을 줄이 기 위하여 Fetch number of record 방식을 적용하였 다. (4)에서는 저주파 성분을 제거하고 부분방전 신호 만 처리하도록 하였으며, 저역 차단 주파수가 $1 \mathrm{kHz}$ 인 디지털 고역 통과필터를 사용하였다. (5)에서는 메모리에
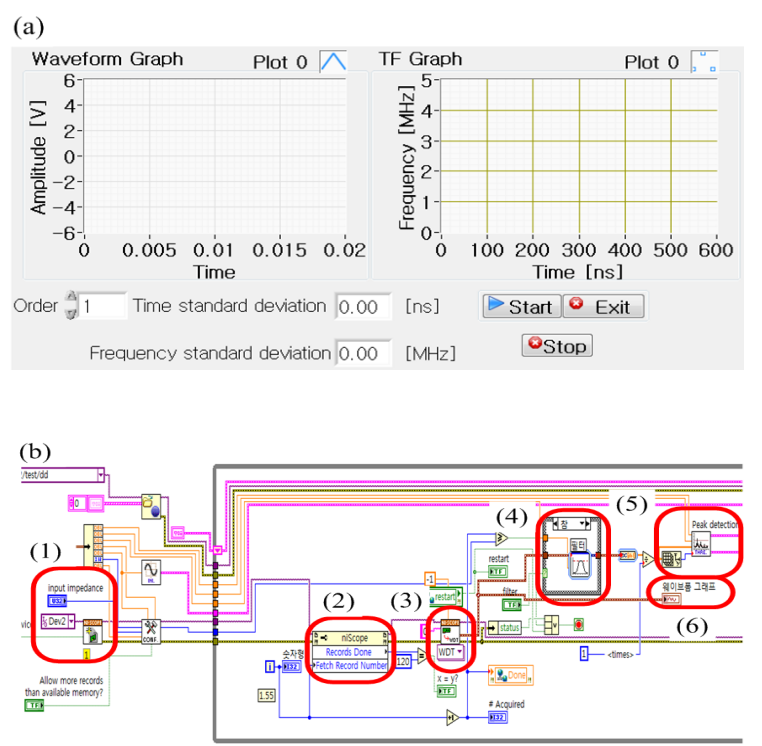

Fig. 2. Analysis program of PD pulses. (a) front panel and (b) block diagram.

저장된 데이터를 시간 영역에 맞추어 재배열한 후, 부분방전 펄스의 크기 및 발생 횟수를 측정하고, (6) 에서 부분방전 신호를 $\mathrm{T}-\mathrm{F}$ map으로 분석하였다.

\section{3 실험계 구성}

실험계는 그림 3 과 같이 고압 변압기 $(220 \mathrm{~V} / 50$ $\mathrm{kV}$ )와 다이오드 및 캐패시터를 사용하여 HVDC 전 원을 구성하였다. 외부 노이즈의 영향을 최소화하기 위하여 차폐함 $[1,020 \mathrm{~mm}(\mathrm{~L}) \times 720 \mathrm{~mm}(\mathrm{~W}) \times 760$ $\mathrm{mm}(\mathrm{H})$ ] 내부에 전극계를 설치하였으며, $\mathrm{SF}_{6}$ 가스를 5 bar로 봉입하였다. $10,000: 1$ 의 분압기를 사용하여 인가전압을 측정하고, $50 \Omega$ 의 무유도 저항으로 전극 계에서 발생하는 부분방전 펄스를 검출하였다.

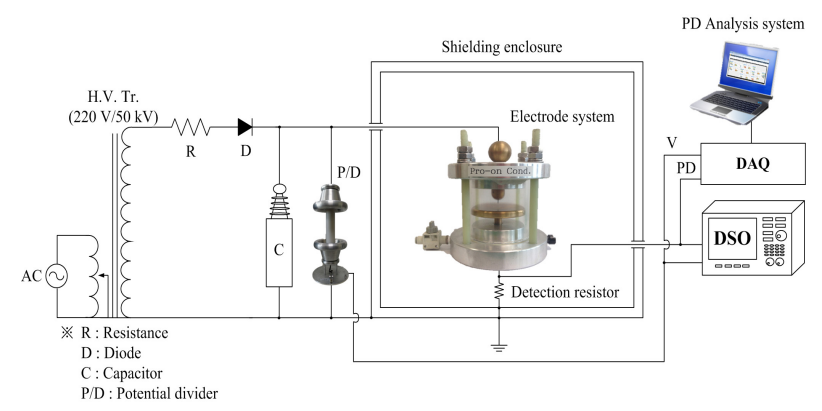

Fig. 3. Configuration of the experimental set-up. 


\section{3. 결과 및 고찰}

도체 돌출에서 측정된 부분방전 펄스와 $\mathrm{T}-\mathrm{F}$ 분석 결과를 그림 4 에 나타내었다. $30 \mathrm{kV}$ 에서 펄스의 크기 는 최대 $52 \mathrm{pC}$, 발생 횟수는 2,410회가 측정되었다. $\mathrm{T}-\mathrm{F}$ map 분석에서 부분방전은 주파수 성분 0.5 $\mathrm{MHz}$ 이하, 펄스폭은 $20 \mathrm{~ns} \sim 35 \mathrm{~ns}$ 사이에 분포하였 다.
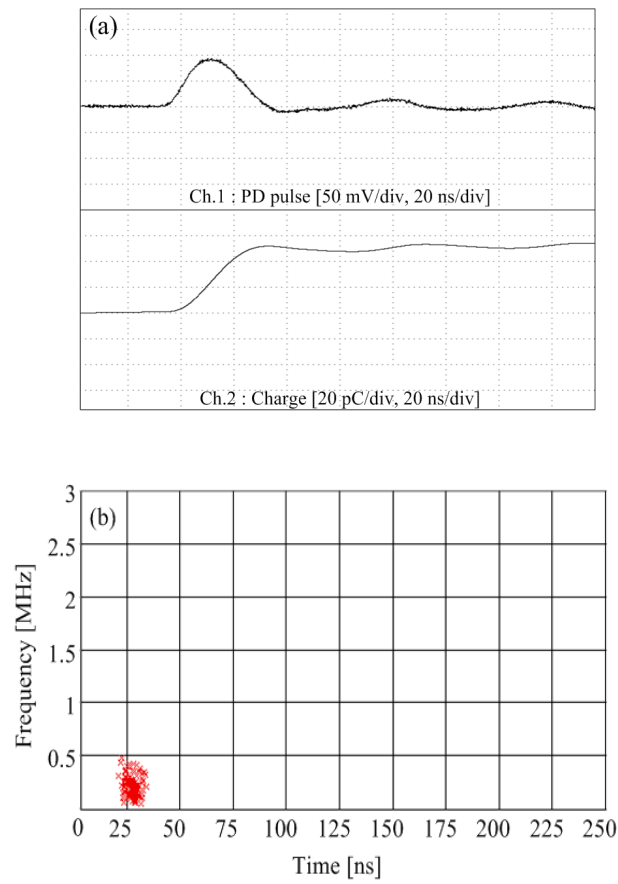

Fig. 4. PD pulses in POC $(30 \mathrm{kV})$. (a) waveform and (b) $\mathrm{T}-\mathrm{F}$ distribution.

외함 돌출의 분석 결과는 그림 5 와 같으며, $30 \mathrm{kV}$ 에서 펄스의 크기와 발생 횟수는 최대 $72 \mathrm{pC}$ 과 400회 가 측정되었다. 펄스의 주파수 성분은 $0.7 \mathrm{MHz} \sim 1.7$ $\mathrm{MHz}$ 와 $0.6 \mathrm{MHz}$ 이하이며, 펄스폭은 $10 \mathrm{~ns} \sim 40 \mathrm{~ns}$ 와 $60 \mathrm{~ns} \sim 125 \mathrm{~ns}$ 에 각각 분포하였다.

크랙에서는 $26 \mathrm{kV}$ 에서 부분방전 펄스가 검출되었 으며, 그림 6에 나타낸 것과 같이 펄스의 크기는 최 대 $150 \mathrm{pC}$, 발생 횟수는 196회이었다. $\mathrm{T}-\mathrm{F}$ 분석 결 과, 주파수 성분은 $0.1 \mathrm{MHz}$ 이하, 펄스폭은 $135 \mathrm{~ns}$ $215 \mathrm{~ns}$ 사이에 분포하였다. 주파수 성분이 낮게 나타 난 이유는 절연물의 정전용량으로 인해 부분방전 펄 스의 진동감쇄 때문인 것으로 판단된다.
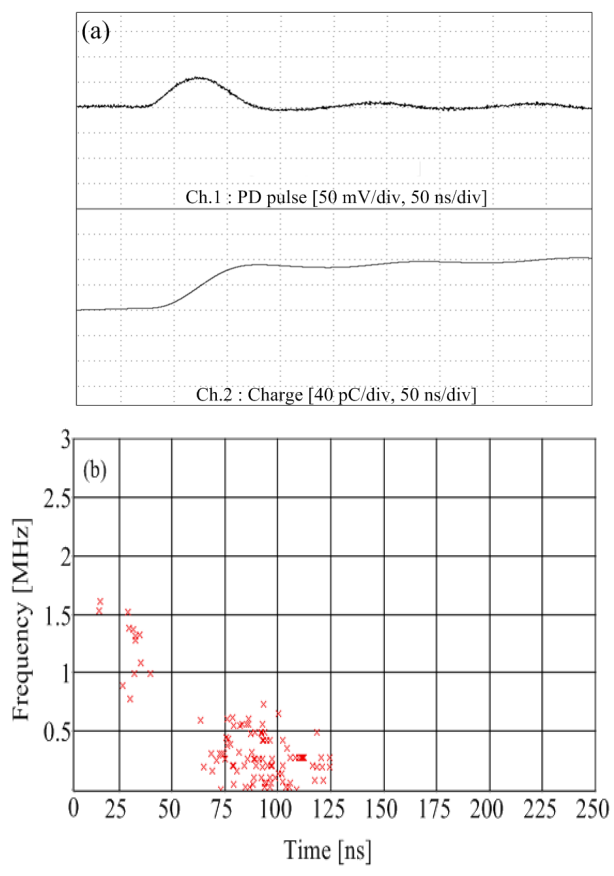

Fig. 5. PD pulses in POE $(30 \mathrm{kV})$. (a) waveform and (b) $\mathrm{T}-\mathrm{F}$ distribution.
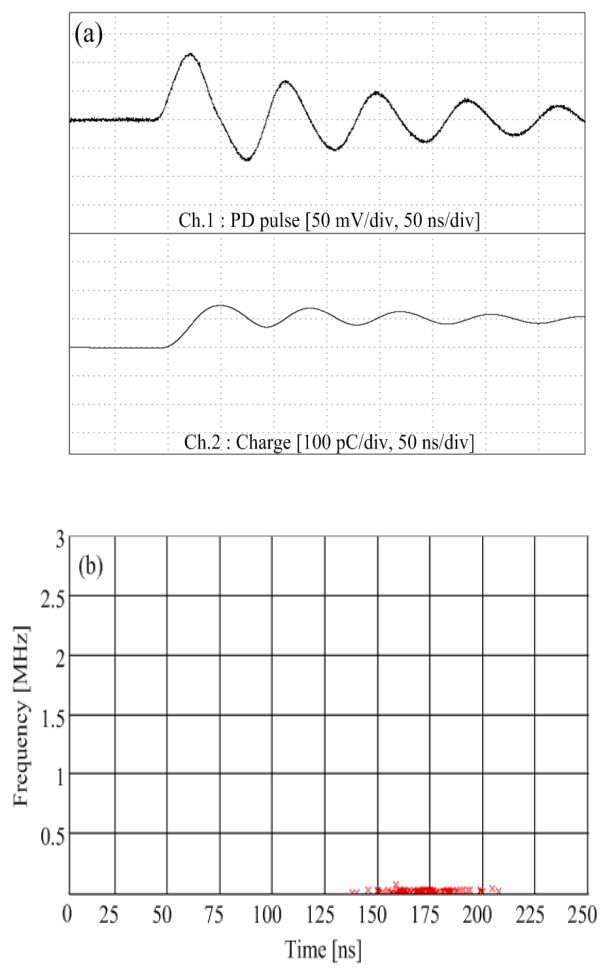

Fig. 6. PD pulses in crack (26 kV). (a) waveform and (b) $\mathrm{T}-\mathrm{F}$ distribution. 

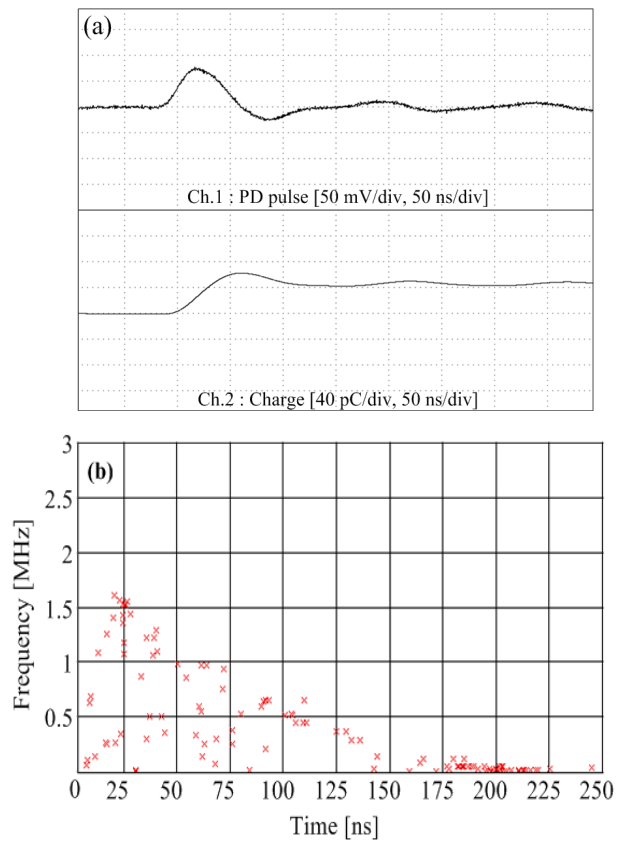

Fig. 7. PD pulses in FP $(22 \mathrm{kV})$. (a) waveform and (b) $\mathrm{T}-\mathrm{F}$ distribution.

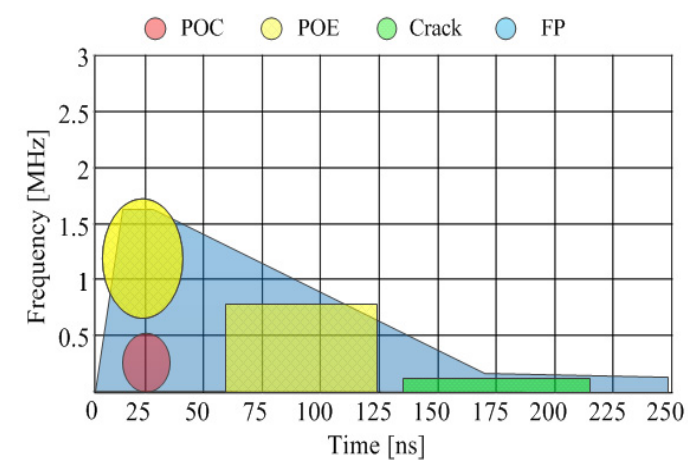

Fig. 8. T-F distributions depending on electrode systems.

자유입자의 측정 결과를 그림 7 에 나타내었다. 22 $\mathrm{kV}$ 에서 부분방전이 발생하였으며, 크기는 최대 62 $\mathrm{pC}$, 발생 횟수는 199회로 측정되었다. $\mathrm{T}-\mathrm{F}$ 분석 결과, 펄스의 주파수 성분은 $1.6 \mathrm{MHz}$ 이하, 펄스폭은 250 $\mathrm{ns}$ 이하에 분포하였다.

결함별 분석 결과를 그림 8에 나타내었다. 도체 돌 출, 외함 돌출 및 크랙에서 발생하는 부분방전 펄스의 주파수 특성과 펄스폭은 서로 겹치지 않는 영역에서 클러스터가 형성되었으나 자유입자는 3 가지 형태의 결함계를 모두 포함하는 영역에 분포하였다.

\section{4. 결 론}

본 논문에서는 절연결함을 모의하기 위하여 4 가지 형태의 전극계를 제작하였으며, 부분방전 펄스를 분 석하기 위하여 T-F map 알고리즘을 설계하였다.

전극계에 $\mathrm{SF}_{6}$ 가스를 $5 \mathrm{bar}$ 로 봉입한 후, 직류 고 전압을 인가하여 부분방전을 발생시켰으며, 전극계에 따른 부분방전 펄스를 시간 영역과 주파수 영역으로 분석하였다.

도체 돌출 전극에서 부분방전 펄스의 주파수 성분 은 $0.5 \mathrm{MHz}$ 이하, 펄스폭은 $20 \mathrm{~ns} \sim 35 \mathrm{~ns}$ 사이에 분포하였으며, 외함 돌출 전극의 주파수 성분은 0.7 $\mathrm{MHz} \sim 1.7 \mathrm{MHz}$ 및 $0.6 \mathrm{MHz}$ 이하, 펄스폭은 $10 \mathrm{~ns} \sim$ $40 \mathrm{~ns}$ 와 $60 \mathrm{~ns} \sim 125 \mathrm{~ns}$ 에 각각 분포하였다. 크랙과 자유입자 전극계의 주파수 성분은 $0.1 \mathrm{MHz}$ 이하와 $1.6 \mathrm{MHz}$ 이하, 펄스폭은 $135 \mathrm{~ns} \sim 215 \mathrm{~ns}$ 와 $250 \mathrm{~ns}$ 이하에서 분포하였다.

상기 결과로부터 전극계에 따른 $\mathrm{T}-\mathrm{F} \mathrm{map}$ 의 클러 스터가 각각 다르게 분석되므로 $\mathrm{HVDC}$ 에서 사용되는 전력설비의 결함별 진단이 가능할 것으로 판단된다.

\section{REFERENCES}

[1] H. Q. Niu, A. Cavallini, and G. C. Montanari, Proc. IEEE Int. Symp. on Electrical Insulation, 373 (2008).

[2] R. Sarathi and G Koperundevi, IEEE Trans. Dielectr. Electr. Insul., 15, 1724 (2008).

[3] U. Schicher, M. Kuschel, and J. Gorablenkow, Proc. Int. Symp. on High Voltage Engineering, 136 (2013).

[4] S. Meijer, P. D. Agoris, J. J. Smit, M. D. Judd, and L. Yang, Proc. Int. Symp. on Electrical Insulation, 416 (2006).

[5] M. H. Yun and K. S. Kim, Proc. the KIEE (World of Electricity) (KIEE, Seoul, Korea, 2014) p. 52.

[6] R. Sarathi, A. V. Giridhar, and K. Sethupathi, IEEE Trans. Dielectr. Electr. Insul., 18, 707 (2011).

[7] J. J. Park, S. Y. Lee, and D. C. Mun, J. KIEEME, 19, 942 (2006).

[8] A. J. Reid, M. D. Judd, R. A. Fouracre, B. G. Stewart, and D. M. Hepburn, IEEE Trans. Dielectr. Electr. Insul., 18, 444 (2011).

[9] G. S. Kil, I. K. Kim, D. W. Park, S. Y. Choi, and C. Y. Park, Current Appl. Phys., 9, 296 (2009).

[10] A. Contin, G. C. Montanari, and A. Cavallini, IEEE 
Trans. Dielectr. Electr. Insul., 7, 30 (2000).

[11] A. Cavallini, G. C. Montanari, F. Puletti, and A. Contin, IEEE Trans. Dielectr. Electr. Insul., 12, 203 (2005).
[12] A. Contin, A. Cavallini, G. C. Montanari, G. Pasini, and F. Puletti, IEEE Trans. Dielectr. Electr. Insul., 9, 335 (2002).

[13] H. K. Cha, J. Y. Lee, D. W. Park, and G. S. Kil, J. KIEEME, 25, 229 (2012). 